\title{
Effect of FIFA 11+ Warm-Up Programme on Physical Performance Parameters in Male Collegiate Football Players: An Evidence based Study
}

\author{
Buch Phalak Pankaj ${ }^{1}$, Manmitkaur A. Gill ${ }^{2}$ \\ ${ }^{1}$ M.P.T. (Sports Sciences), ${ }^{2}$ M.P.T. (Musculoskeletal), Ph.D Scholar, Gujarat University. Senior lecturer, \\ Government Spine Institute and Government Physiotherapy College, Civil Hospital, Asarwa, Ahmedabad. \\ Corresponding Author: Buch Phalak Pankaj
}

\begin{abstract}
Background: Football is defined to be a physically demanding sport that entails sudden acceleration and deceleration, rapid changes in direction, jumping and landing tasks, also as many situations in which players are involved in tackling to stay possession of or to win the ball. Between 2006 and 2008, FIFA Medical Assessment and Research Centre (F-MARC) developed a neuromuscular warmup programme \&injury prevention program with subsequent enhancement of performance for soccer called the FIFA 11+.The FIFA 11+ programme has been shown to be an efficient means of achieving optimal physiological readiness for sport.

Purpose: The purpose is to study the scientific evidences regarding the effect of the 11+ warm -up programme on physical performance parameters in male recreational football players.

Methodology: A search for relevant articles was carried out using key words- and search enginesPEDro, Pubmed, Science direct, Google scholar, ResearchGate, Wiley library, The Cochrane library. Studies were selected from year 2010-2019. 15 articles were reviewed and included in which study.

Results: 13 articles concluded that "FIFA 11+" prevention programme can be considered an appropriate warm-up, inducing improvements in football players. (level of evidence :1a,1b,2a,2b) There are 2 high quality of evidences. (Randomized control trial, Pre-post intervention Comparative study-1b) which suggests that that a soccer specific warm-up protocol relied on dynamic stretching and dynamic warm up is preferable in enhancing performance as compared to protocols relying on static stretches , FIFA 11+ program and other injury prevention programme.

Conclusion: Based on evidences collected and analyzed it can be concluded that FIFA 11+ warming up program is soccer specific warming-up program which includes running, strength, plyometric, balance, and agility components which apart from being an effective injury prevention programme it has effective potential to enhance the physical performance of a player in parameters like VO2max, Strength, Balance, Flexibility, Agility etc.

Clinical Implication: FIFA 11+ warming up program is soccer specific warming-up program which includes running, strength, plyometric, balance, and agility components. It has effective potential to enhance the performance of a player. Also FIFA 11+ warming up program is easy to be coach and train because it is well organized and structured to follow in every training session and can replace in place of traditional warm- ups.
\end{abstract}

Key Words: fifa 11+ warm-up, male football players, soccer, physical performance, neuromuscular parameters

\section{INTRODUCTION}

Football (Soccer/gridiron) is one among the oldest sports within the world.
The aim of football is to attain more goals than your opponent in a 90 minute playing time-frame. The match is break up into two 
halves of 45 minutes. After the primary 45 minutes players will take a 15 minute respite called half time. The second 45 minutes will resume and any time deemed fit be added on by the referee (injury time) are going to be accordingly. Each team consists of 11 players. These are made from one goalkeeper and ten outfield players. Football may be a physically demanding sport that entails sudden acceleration and deceleration, rapid changes in direction, jumping and landing tasks, also as many situations during which players are involved in tackling to stay possession of or to win the ball. ${ }^{[1,2]}$ it's a high-intensity, complex sport with long-lasting intervals of exercise. ${ }^{[3]}$ the sport predominantly relies on the aerobic energy system but during the game variety of skills like jumping, kicking, turning and sprinting which challenge the neuromuscular system also are required ${ }^{[3] \text {. }}$

A warming up exercises generally consists of a gradual increase in intensity, physical activity, joint mobility exercise, stretching and sport related activity ${ }^{[4]}$. Warming up exercises is a process which brought to a condition at which it safely responds to the nerve impel of the person for a quick and efficient action ${ }^{[5]}$. A warming up is generally used to prepare athletes for participation in a sporting event. Warming up programs usually consist of mild or moderate exercises that are geared toward enhancing the performance of the athlete.

F-MARC developed FIFA -11+ It consists of three parts with total of 27 exercises, which should be performed in specified sequence at start of every training sessions. FIFA $11+$ is effective in reducing lower extremity injury rates (mainly knee) in teams practicing this warm up at least twice a week for longer than three consecutive months. ${ }^{[6-11]}$ For any warm-up programme to be successful it has to be an effective means of preparing the players for football. It must even be enjoyable and practical for the players and coaches to perform. The FIFA $11+$ has been shown to be efficient means of achieving optimal physiological readiness for sport. ${ }^{[12-13]}$ This program was designed to prevent injuries in players lower limbs. The required time to perform this program is $20-25$ minutes. This program consists of three parts. The first part includes 8 minutes jogging. The second part contains six types of strength training, balance exercise and jumping exercises with time duration of 15 minutes at three elementary, intermediate and advanced levels. The final section includes speed running combined by bounding, planting and cutting movements (speed running with sudden change of direction). This section lasts 2 minutes ${ }^{[14]} .20$ minute warm-up that consists of 27 exercises, including (1) running, (2) strength, plyometric and balance (3) additional running components. Throughout the program there is focus on cutting, jumping and landing technique.

This helps to know and understand the current fitness which includes aspects such as cardiovascular endurance, muscular strength, muscular endurance, softness and body composition, fitness on treatment involves coordination, balance, agility, power, reaction time and quickness. Those who are involved in sports or game require high fitness level to achieve excellent performance limited individual or team. ${ }^{[15-}$ 16]

\section{METHODOLOGY}

Study Type: This is an Evidence Based Study, conducted according to Preferred Reporting Items for Systematic Reviews and Meta-analysis (PRISMA) guidelines (Figure 1).

Search strategy: The search engines used to find the appropriate articles were: PEDro, Pubmed, Science direct, Google scholar, ResearchGate, Wiley library, The Cochrane library

Key words used for the search were: FIFA $11+$ warm-up, male football players, soccer, physical performance, neuromuscular parameters

Eligibility criteria: Articles were selected from last 10 years (2010-2019). Total 32 articles were viewed out of 
Buch Phalak Pankaj et.al. Effect of FIFA 11+ warm-up programme on physical performance parameters in male collegiate football players: an evidence based study.

which 15 were included and reviewed for evidence (Table 1). Other articles were excluded because they had Age group $<14$ years, Gender: female, Different outcome measure like injury prevention, Efficacy seen in different sport other than football and soccer, Other intervention added with FIFA11+.

Data Analysis: All 15 articles were assessed using 2 scales:

1. The PEDro scale: It assesses methodological quality and consists of a checklist of 11 criteria, 10 of which are scored. For each criterion the study met, 1 point was awarded. The points were tallied and presented as a score out of 10. The scale applies only to experimental studies. For this review, investigations with PEDro scores of 6 to
10 were considered high quality, of 4 to 5 were considered moderate quality, and of 0 to 3 were considered low quality. The PEDro score has demonstrated 'fair' to 'excellent' inter-rater reliability (Intraclass Correlation Coefficient 0.530.91) for randomized controlled trials of physiotherapy interventions. Convergent validity is supported for the PEDro score through correlation with other quality rating scales including: the Jadad scale (0.35) and van Tulder 2003 scale (0.71) for clinical trials of physiotherapy related interventions. ${ }^{[7]}$ (Appendix 1)

2. The CEBM's Levels of Evidence scale: It assesses quality based on study design, which categorize the studies in a scale ranging from 1 to 5 with further subdivision for each. (Appendix 2)

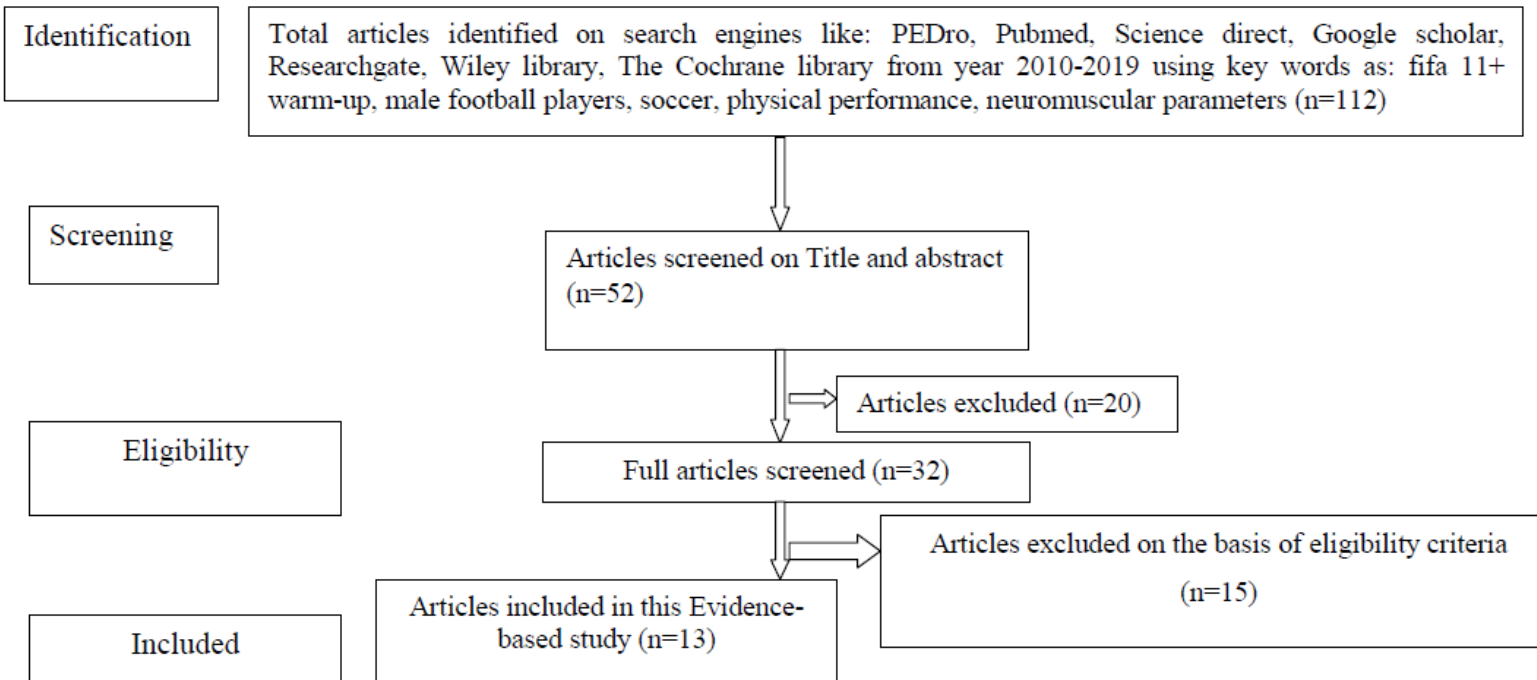

Figure 1: Preferred Reporting Items for Systematic reviews and Meta-analysis (PRISMA)

\section{Characteristics of included studies}

\begin{tabular}{|l|l|l|l|l|}
\hline $\begin{array}{l}\text { First Author } \\
\text { Name And } \\
\text { Year }\end{array}$ & Outcome Measure & Conclusion & $\begin{array}{l}\text { Sample } \\
\text { Size }\end{array}$ & $\begin{array}{l}\text { PEDro } \\
\text { eevel of } \\
\text { evidence }\end{array}$ \\
\hline $\begin{array}{l}\text { C Hanlon }{ }^{[17]} \\
2020\end{array}$ & $\begin{array}{l}\text { Force generation Coordination } \\
\text { Posture Balance } \\
\text { Soccer specific skills } \\
\text { Agility } \\
\text { Speed } \\
\text { MuscleStrength }\end{array}$ & $\begin{array}{l}\text { injury prevention programs improve several } \\
\text { modifiable intrinsic risk factors of lower } \\
\text { extremity performance among youth } \\
\text { athletes, particularly force generation. }\end{array}$ & $\begin{array}{l}8 \\
\text { studies }\end{array}$ & - \\
$\begin{array}{l}\text { N. } \\
\text { Barengo }{ }^{[18]}\end{array}$ & $\begin{array}{l}\text { Injury-Incidence rate Neuromuscular } \\
\text { performance changes } \\
\text { Cost-effectiveness } \\
\text { Method of delivery }\end{array}$ & $\begin{array}{l}\text { FIFA 11+ can be considered as a } \\
\text { fundamental tool to minimize the risks of } \\
\text { participation in a sport with substantial } \\
\text { health benefits }\end{array}$ & $\begin{array}{l}13 \\
\text { studies }\end{array}$ & - \\
\hline
\end{tabular}


Buch Phalak Pankaj et.al. Effect of FIFA 11+ warm-up programme on physical performance parameters in male collegiate football players: an evidence based study.

\begin{tabular}{|c|c|c|c|c|c|}
\hline $\begin{array}{l}\text { M. Bizzini }{ }^{[12]} \\
2013\end{array}$ & 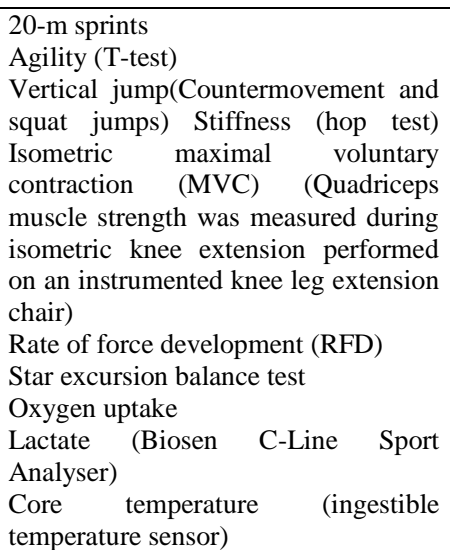 & $\begin{array}{l}\text { "FIFA 11+" prevention programme can be } \\
\text { considered an appropriate warm-up, } \\
\text { inducing improvements in football players } \\
\text { comparable with those obtained with other } \\
\text { warm-up routines reported in the literature. }\end{array}$ & $\begin{array}{l}11 \\
\text { articles }\end{array}$ & - & $1 \mathrm{a}$ \\
\hline $\begin{array}{l}\text { Ayala }^{[19]} \\
2017\end{array}$ & $\begin{array}{l}\text { Joint range of motion(passive hip } \\
\text { flexion (passive straight leg raise test), } \\
\text { knee flexion (Modified Thomas test) } \\
\text { and ankle dorsiflexion (weight- } \\
\text { bearing lunge with knee extended test } \\
\text { ) } \\
\text { Dynamic postural control(Y-Balance } \\
\text { test Single legged hop limb } \\
\text { symmetry (1) the single hop for } \\
\text { distance (single hop); and } 2 \text { ) triple hop } \\
\text { for distance (triple hop) Sprint } \\
\text { time(10 and } 20 \text { m sprint) } \\
\text { Jumping height (Vertical drop jump) } \\
\text { Agility(Illinois agility test) }\end{array}$ & $\begin{array}{l}\text { Exchanging traditional warm-up } \\
\text { programmes for the FIFA 11+ in male } \\
\text { youth soccer players based on its superior } \\
\text { effects on some neuromuscular parameters } \\
\text { (sprinting, jumping and stability) of } \\
\text { physical performance. }\end{array}$ & 41 & 7 & $1 \mathrm{~b}$ \\
\hline $\begin{array}{l}\text { Franco } M^{[20]} \\
2013\end{array}$ & 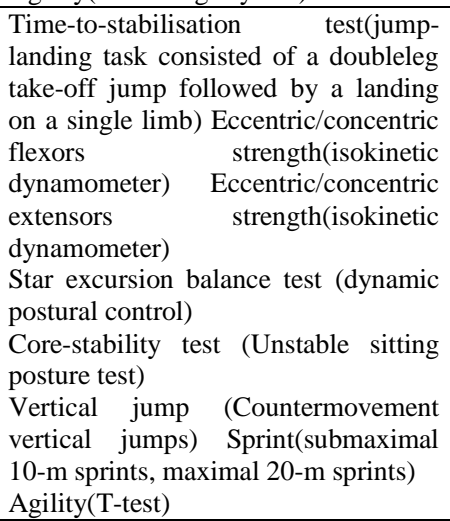 & $\begin{array}{l}\text { Performing "FIFA 11+" for } 9 \text { weeks can } \\
\text { improve neuromuscular control. }\end{array}$ & 81 & 6 & $1 \mathrm{~b}$ \\
\hline $\begin{array}{l}\text { A.Naweda }{ }^{[2]]} \\
2018\end{array}$ & $\begin{array}{l}\text { Vertical jump } \\
20 \text {-yard sprint run Illinois agility } \\
\text { (Illinois run test, t-test) }\end{array}$ & $\begin{array}{l}\text { FIFA 11+ program may improve the } \\
\text { performance of young amateur soccer } \\
\text { players. }\end{array}$ & 57 & 6 & $1 \mathrm{~b}$ \\
\hline $\begin{array}{l}\text { S. Arsenis } \\
2020\end{array}$ & $\begin{array}{l}\text { Biodex Stability System(lower limb } \\
\text { balance ability) Isokinetic knee joint } \\
\text { moment measurements concentric } \\
\text { flexors/extensors and eccentric flexors } \\
\text { performed at two different angular } \\
\text { velocities, first at } 60 \% \text { and then at } \\
180 \% \text { s(strength) }\end{array}$ & $\begin{array}{l}\text { Application of the FIFA } 11+\text { injury } \\
\text { prevention program for } 8 \text { weeks can } \\
\text { improve lower limbs balance ability and } \\
\text { hamstrings muscle strength, elements which } \\
\text { are very important for prevention of } \\
\text { hamstring muscle strains and lower limb } \\
\text { ligament injuries in soccer. }\end{array}$ & 32 & 7 & $1 \mathrm{~b}$ \\
\hline $\begin{array}{l}\text { Daneshjoo } \\
\mathrm{A}^{[23]} \\
2013\end{array}$ & $\begin{array}{l}\text { Hamstrings and Quadriceps strength } \\
\text { (Biodex Isokinetic Dynamometer) }\end{array}$ & $\begin{array}{l}\text { The } 11+\text { programme is more advantageous } \\
\text { for its greater concentric hamstring strength } \\
\text { improvement compared to the HarmoKnee } \\
\text { programme. }\end{array}$ & 36 & 5 & $2 a$ \\
\hline $\begin{array}{l}\text { A.Daneshjoo } \\
2012^{[24]}\end{array}$ & $\begin{array}{l}\text { Proprioception 30 degree, } 45 \text { degree } \\
\text { and 60degree knee flexion (Biodex } \\
\text { Isokinetic Dynamometer) } \\
\text { Static balance (Stork stand test) } \\
\text { Dynamic balance (Star Excursion } \\
\text { Balance Test (SEBT) }\end{array}$ & $\begin{array}{l}\text { Both the } 11+\text { and HarmoKnee programs } \\
\text { were proven to be useful warm-up protocols } \\
\text { in improving proprioception at } 45 \text { degree } \\
\text { and } 60 \text { degree knee flexion as well as static } \\
\text { and dynamic balance in professional male } \\
\text { soccer players. }\end{array}$ & 36 & 5 & $2 a$ \\
\hline $\begin{array}{l}\text { A. Mokhtar } \\
2013^{[25]}\end{array}$ & $\begin{array}{l}10 \mathrm{~m} \text { speed tests with and without a } \\
\text { ball } 20 \mathrm{~m} \text { single sprint } \\
\text { vertical jump } \\
\text { Wall-Volley test } \\
\text { Illinois agility test }\end{array}$ & $\begin{array}{l}\text { 8-weeks performing the } 11+\text { warm-up } \\
\text { program can enhance jump height, agility } \\
\text { and soccer skill while the HarmoKnee } \\
\text { program generally only improves soccer } \\
\text { skill in young professional male soccer } \\
\text { players }\end{array}$ & 36 & 5 & $2 a$ \\
\hline
\end{tabular}


Buch Phalak Pankaj et.al. Effect of FIFA 11+ warm-up programme on physical performance parameters in male collegiate football players: an evidence based study.

\begin{tabular}{|c|c|c|c|c|c|}
\hline $\begin{array}{l}\text { J Britoa }^{[26]} \\
2010\end{array}$ & $\begin{array}{l}\text { Isokinetic measurements were } \\
\text { performed on the hamstrings and } \\
\text { quadriceps muscles on both lower } \\
\text { extremities at concentric 60/s and } \\
180 / \mathrm{s} \text { and eccentric } 30 / \mathrm{s} \text {. The peak } \\
\text { torque (PT) as well as conventional } \\
\text { and dynamic control ratios (DCR) }\end{array}$ & $\begin{array}{l}\text { Subelite soccer players improved strength } \\
\text { and muscle balance in the knee extensor } \\
\text { and flexor muscles by performing "The } \\
11+\text { " injury prevention programme, } \\
\text { suggesting that the programme might have } \\
\text { the potential to decrease the risk of } \\
\text { hamstring and knee injuries among soccer } \\
\text { players. }\end{array}$ & 20 & - & $2 \mathrm{c}$ \\
\hline $\begin{array}{l}\text { J. Hwang } \\
2019^{[27]}\end{array}$ & $\begin{array}{l}10-\mathrm{m} \text { and } 30-\mathrm{m} \text { sprint test, } \\
\text { Coordination test, Arrowhead agility } \\
\text { test, Yo-Yo intermittent recovery test } \\
\text { level } 1 \text { (Yo-Yo IR test level 1) } \\
\text { Functional movement Screen }\end{array}$ & $\begin{array}{l}\text { A } 12 \text {-week FIFA } 11+\text { training program had } \\
\text { positive effects on soccer-specific physical } \\
\text { performance and functional movement of } \\
\text { collegiate male soccer players. }\end{array}$ & 20 & 7 & $1 b$ \\
\hline $\begin{array}{l}\text { A.Sharma } \\
2016\end{array}$ & $\begin{array}{l}20 \mathrm{~m} \text { speed test } \\
\text { Vertical jump test Illinois agility test } \\
\text { Wall volley test }\end{array}$ & $\begin{array}{l}\text { 11+ injury prevention program can be } \\
\text { implemented to enhance agility and vertical } \\
\text { jump in young male football players. }\end{array}$ & 45 & 5 & $2 a$ \\
\hline $\begin{array}{l}\text { Vazini Taher } \\
\mathrm{A}^{[29]} 2017\end{array}$ & $\begin{array}{l}\text { Illinois Agility Test Vertical jump } \\
30 \text { meter sprint Consecutive turns } \\
\text { Flexibility of knee }\end{array}$ & $\begin{array}{l}\text { A soccer specific warm-up protocol relied } \\
\text { on dynamic stretching is preferable in } \\
\text { enhancing performance as compared to } \\
\text { protocols relying on static stretches and } \\
\text { FIFA } 11+\text { program }\end{array}$ & 22 & 7 & $1 \mathrm{~b}$ \\
\hline $\begin{array}{l}\text { Ayala } F^{[30]} \\
2017\end{array}$ & $\begin{array}{l}\text { Hip, knee and ankle range of motions } \\
\text { Conventional and functional } \\
\text { hamstring-to-quadriceps strength } \\
\text { ratios } \\
10 \text { and } 20 \text { meters sprint time } \\
\text { Drop vertical jump height } \\
\text { Reactive strength index }\end{array}$ & $\begin{array}{l}\text { Neither the FIFA } 11+\text { nor the Harmoknee } \\
\text { routines appear to be preferable to dynamic } \\
\text { warm-up routines currently performed by } \\
\text { most football players prior to training } \\
\text { sessions and matches. }\end{array}$ & 16 & 7 & $1 \mathrm{~b}$ \\
\hline
\end{tabular}

\section{RESULTS}

Evidences were reviewed and analysis was done on the basis of PEDro score and CEBM's Level of Evidence Scale.

1. Out of 15 articles reviewed, 13 articles concluded that "FIFA 11+" prevention programme can be considered an appropriate warm-up, inducing improvements in football players which consisted of 1 Meta analysis, 2 Systematic reviews, 9 (moderate to high quality) RCT,1 cohort study.

2. Out of 15 articles reviewed, 2 high quality RCT suggested that a soccer specific warm-up protocol relied on dynamic stretching and dynamic warm up is preferable in enhancing performance as compared to protocols relying on static stretches, FIFA 11+ program and other injury prevention programme.

\section{DISCUSSION}

In past years, particularly within recreational and amateur sport environments, warmups were typically employed to serve only two purposes: prepare the athlete mentally, and to prepare the athlete physically for exercise or competition. However, in recent years whilst the same principles apply, warm-ups are now often viewed to serve four primary purposes: Mental readiness, Physical readiness, Injury prevention and Performance enhancement. In professional and elite sport environments, using warmups to serve these four primary purposes appears to now be quite common. As a consequence, warm-ups have evolved to also function a way of enhancing performance and reducing or preventing the occurrence of injury. This type of preparatory exercises or movements is generally referred to as warm-up. Sports competitors and their coaches firmly believe that it is necessary to incorporate some form of preliminary activity or exercises before taking part in any strenuous event. Such preliminary exercises become part of their routine, whether in training or in competition. Warm-up is taken into account to be a critical factor and is often employed by athletes so as to avoid injuries and achieve high performance during training and competition.

Warm-up consists of a general and a selected part. The general part focuses on the rise of the core and muscle temperature, cellular metabolism and therefore the joint range of motion. The specific part focuses 
on the reinforcement of the motor programs and mainly on the activity that it follows.

Total 15 studies were reviewed from various data sources and included in this evidence based study. The methodological qualities of included studies were high to low.

13 articles concluded that "FIFA $11+$ " prevention programme can be considered an appropriate warm-up, inducing improvements in football players. (level of evidence :1a, 1b, 2a, 2b) There is 1 strong scientific evidence (meta analysis-1a) suggests that effect of FIFA 11+ when compared with other warm up the "FIFA 11 + ", in addition to being potentially effective for reducing the risk of injuries, was seen to be also adequate for inducing positive acute physiological responses that can enhance the following performance. Therefore, the "FIFA $11+$ " (and specifically the level 3) can be considered an appropriate warm-up inducing improvements comparable those obtained with other warm-up routines in football players. There is 2 strong scientific evidences (systemic review-1a) suggests that "FIFA 11+" injury prevention programs improve several modifiable intrinsic risk factors of lower extremity performance among soccer athletes and improves several soccer specific skills and several physical performance parameters .

Also Players with high compliance to the FIFA 11+program had an estimated risk reduction of all injuries by $35 \%$ and show significant improvements in components of neuromuscular and motor performance when participating in structured warm up sessions a minimum of 1.5 times/week. There are 10 moderate to high quality of evidences. (Randomized control trial, Cohort study, Pre-post intervention Comparative study-1b, 2a, 2b) Which suggests FIFA $11+$ training program had positive effects on certain soccerspecific skills like Agility, static balance, Dynamic balance, Sprint time, Jump distance, Accuracy when kicking a ball, Hamstring flexibility, H/Q ratio ,injury rate and muscle length etc. There are 2 high quality of evidences. (Randomized control trial, Pre-post intervention Comparative study-1b) which suggests that that a soccer specific warm-up protocol relied on dynamic stretching and dynamic warm up is preferable in enhancing performance as compared to protocols relying on static stretches, FIFA 11+ program and other injury prevention programme.

\section{CONCLUSION}

Based on evidences collected and analyzed it can be concluded that FIFA 11+ warming up program is soccer specific warming-up program which includes running, strength, plyometric, balance, and agility components which apart from being an effective injury prevention programme it has effective potential to enhance the physical performance of a player in parameters like VO2max, Strength, Balance, Flexibility, Agility etc

\section{Clinical Implication:}

Soccer practitioners require many attributes to become successful players. These include cardiovascular fitness, muscular strength, muscular endurance, flexibility, agility, coordination, skill and tactical knowledge. Based on an abundance of research, it is widely understood and accepted that warming up prior to activity is important and beneficial which is used to prepare athletes for participation prior to sporting event. Thus FIFA 11+ warming up program is soccer specific warming-up program which includes running, strength, plyometric, balance, and agility components. It has effective potential to enhance the performance of a player. Also FIFA $11+$ warming up program is easy to be coach and train because it is well organized and structured to follow in every training session and can replace in place of traditional warm- ups.

\section{CONFLICT OF INTEREST}

There is no conflict of interest.

\section{ETHICAL APPROVAL}

Ethical approval was not required. 


\section{ABBREVIATIONS}

FIFA: Fédération Internationale de Football Association, F-MARC: FIFA- Medical Assessment and Research Centre, ACL: Anterior Cruciate Ligament, PEDro: Physiotherapy Evidence Database Scale Scores, CINAHL: Cumulative Index of Nursing and Allied Health Literature, CEBM: Centre of Evidence-Based Medicine, EBSCO: Elton Bryson Stephens Company, H/Q: Hamstring/Quadricep, SEBT: Star Excursion Balance Test, PT: Peak Torque, FMS: Functional Movement Screen, MVC: Maximal Voluntary Contraction, RFD: Rate of Force Development, DCR: Dynamic Control Ratios, DWU: Dynamic Warm-Up, RCT: Randomized Controlled Trial

\section{Acknowledgement: None}

\section{Source of Funding: None}

\section{REFERENCES}

1. Faude $\mathrm{O}$, Rößler R, Junge A. Football injuries in children and adolescent players: are there clues for prevention? Sports Med (2013) 43

2. Krustrup P, Aagaard P, Nybo L, Petersen J, Mohr M, Bangsbo J. Recreational football as a health promoting activity: a topical review. Scand J Med Sci Sports (2010) 20

3. Arnason, A., Andersen, T.E., Holme, I., Engebretsen, L. and Bahr, R. (2008): Prevention of hamstring strains in elite soccer: an intervention study. Scandinavian Journal of Medicine and Science in Sports 18, pp 40-48.

4. McNair PJ, Stanley SN. Effect of passive stretching and jogging on the series elastic muscle stiffness and range of motion of the ankle joint. Br J Sports Med. 1996 Dec;30(4):313-7

5. Bishop, D. (2003): Performance changes following active warm up and how to structure the warm up. Journal of Sports Medicine 33(7), pp 483-498.

6. Silvers H, Mandelbaum B, Bizzini M, Dvorak J. The efficacy of the FIFA 11+ program in the collegiate male soccer player (USA). $\mathrm{Br} \quad \mathrm{J}$ Sports Med. 2014;48:662.

7. Soligard T, Myklebust G, Steffen K, Holme I, Silvers H, Bizzini $M$, et al. Comprehensive warm-up programme to prevent injuries in young female footballers: cluster randomised controlled trial. BMJ. 2008;337.

8. Steffen K, Emery CA, Romiti M, Kang J, Bizzini M, Dvorak j, et al. High adherence to a neuromuscular injury prevention programme (FIFA 11+) improves functional balance and reduces injury risk in Canadian youth female football players: a cluster randomised trial. $\mathrm{Br} \mathrm{J}$ Sports Med. 2013;47:794-802.

9. van Beijsterveldt AM, van de Port IG, Krist MR, Schmikli SL, Stubbe JH, Frederiks JE, et al. Effectiveness of an injury prevention programme for adult male amateur soccer players: a clusterrandomised controlled trial. $\mathrm{Br} \mathrm{J}$ Sports Med. 2012;0:1-6.

10. Reilly, T., \& Thomas, T. (1976). A motion analysis of work-rate in different positional roles in professional football match-play. Journal of Human Movement Studies, 2, $87-97$.

11. McDonald, L. G. (1951). The construction of a kicking test as an index of general soccer ability. Master's thesis, Springfield College, Springfield, Mass. In Miller, D. K. (2002). Measurement by the Physical Educator: Why and How (4th ed.). New York: McGraw-Hill. Page 253.

12. Bizzini M, Impellizzeri FM, Dvorak J, et al. Physiological and performance responses to the "FIFA 11+" (part 1): Is it an appropriate warm-up? J Sports Sci. 2013;31(13):1481-1490.

13. Impellizzeri FM, Bizzini MF, Dvorak JF, Pellegrini BF, Schena FF, Junge A. Physiological and performance responses to the FIFA 11+ (part 2): A randomised controlled trial on the training effects. Journal of sports sciences (1466447).

14. Bizzini M, Junge A, Dvorak J. 11+ Manual A complete warm-up programme to prevent injuries. Zurich: FIFA Medical Assessment and Research Centre; 2011. 
Buch Phalak Pankaj et.al. Effect of FIFA 11+ warm-up programme on physical performance parameters in male collegiate football players: an evidence based study.

15. Bompa, T.O. and Haff, G.G. (2009): Periodization in Theory and Methodology of Training. Human Kinetics, Champaign. $\mathrm{pp} 200$

16. Mohar, Kassim \& Rahman, Fariq. (2018). The Importance of Post-Activation Potentiation (PAP) Training on Physical Fitness Preparation for Malaysian Female Hockey Players. International Journal of Engineering \& Technology. 7. 293.

17. Hanlon C, Krzak JJ, Prodoehl J, Hall KD. Effect of Injury Prevention Programs on Lower Extremity Performance in Youth Athletes: A Systematic Review. Sports Health. 2020;12(1):12-22.

18. Barengo NC, Meneses-Echávez JF, Ramírez-Vélez R, Cohen DD, Tovar G, Bautista JE. The impact of the FIFA 11+ training program on injury prevention in football players: a systematic review. Int $\mathbf{J}$ Environ Res Public Health. 2014;11(11): 11986-12000.

19. Ayala F, Pomares-Noguera C, RoblesPalazón FJ, et al. Training Effects of the FIFA $11+$ and Harmoknee on Several Neuromuscular Parameters of Physical Performance Measures. Int J Sports Med. 2017;38(4):278-289.

20. Impellizzeri FM, Bizzini M, Dvorak J, Pellegrini B, Schena F, Junge A. Physiological and performance responses to the FIFA $11+$ (part 2): a randomised controlled trial on the training effects. J Sports Sci. 2013;31(13):1491-1502.

21. Nawed A, Khan IA, Jalwan J, Nuhmani S, Muaidi QI. Efficacy of FIFA 11+ training program on functional performance in amateur male soccer players. J Back Musculoskelet Rehabil. 2018;31(5):867870.

22. Daneshjoo A, Mokhtar A, Rahnama N, Yusof A. The effects of injury prevention warm-up programmes on knee strength in male soccer players. Biol Sport. 2013;30(4):281-288.

23. Daneshjoo A, Mokhtar AH, Rahnama N, Yusof A. The effects of comprehensive warm-up programs on proprioception, static and dynamic balance on male soccer players. PLoS One. 2012;7(12)
24. Daneshjoo A, Mokhtar AH, Rahnama N, Yusof A. Effects of the 11+ and Harmoknee Warm-up Programs on Physical Performance Measures in Professional Soccer Players. J Sports Sci Med. 2013;12(3):489-496. Published 2013 Sep 1.

25. Brito, João \& Figueiredo, Pedro \& Fernandes, Luis \& Seabra, André \& Soares, Jose \& Krustrup, Peter \& Rebelo, António. (2010). Isokinetic strength effects of FIFA's "The 11+" injury prevention training programme. Isokinetics and exercise science. 18. 211215.

26. Hwang, Juyoung \& Kim, Jooyoung. (2019). Effect of FIFA 11+ Training Program on Soccer-Specific Physical Performance and Functional Movement in Collegiate Male Soccer Players: A Randomized Controlled Trial. Exercise Science. 28. 141-149.

27. Daneshjoo A, Mokhtar AH, Rahnama N, Yusof A. Effects of the $11+$ and Harmoknee Warm-up Programs on Physical Performance Measures in Professional Soccer Players. J Sports Sci Med. 2013;12(3):489-496.

28. Archna Sharma, Asim Sayyad . Effects of the fifa $11+$ and harmoknee warm-up programs on physical performance measures in elite football players. The Physiotherapy, 2016, Volume:01, Issue:1 $1-6$

29. Vazini Taher A, Parnow A. Level of functional capacities following soccerspecific warm-up methods among elite collegiate soccer players. J Sports Med Phys Fitness. 2017;57(5):537-542.

30. Ayala F, Calderón-López A, DelgadoGosálbez JC, et al. Acute Effects of Three Neuromuscular Warm-Up Strategies on Several Physical Performance Measures in Football Players. PLoS One. 2017;12(1)

How to cite this article: Buch PP, Gill MA. Effect of FIFA 11+ warm-up programme on physical performance parameters in male collegiate football players: an evidence based study. Int J Health Sci Res. 2021;11(8):149-157. DOI: https://doi.org/10.52403/ijhsr.20210822 
Buch Phalak Pankaj et.al. Effect of FIFA 11+ warm-up programme on physical performance parameters in male collegiate football players: an evidence based study.

\section{APPENDIX 1-PEDro SCALE}

\begin{tabular}{|l|l|l|}
\hline No. & Description & Yes / No \\
\hline 1 & Eligibility criteria were specified (No points awarded) & \\
\hline 2 & Subjects were randomly allocated to groups & \\
\hline 3 & Allocation was concealed & \\
\hline 4 & The groups were similar at baseline regarding the most important prognostic indicators & \\
\hline 5 & There was blinding of all subjects & \\
\hline 6 & There was blinding of all therapists who administered the therapy & \\
\hline 7 & There was blinding of all assessors who measured at least one key outcome & \\
\hline 8 & Measure of at least one key outcome were obtained from more than 85\% of the subjects initially allocated to groups & \\
\hline 9 & All subjects for whom outcome measures were available received the treatment or control condition as allocated & \\
\hline 10 & The result of between group comparisons are reported for at least one key outcome & \\
\hline 11 & The study provides both point measures and measures of variability for at least one key outcome \\
\hline
\end{tabular}

\section{APPENDIX 2- CEBM'S LEVEL OF EVIDENCE}

\begin{tabular}{|l|l|}
\hline Level & Definition \\
\hline 1a & Systematic reviews of randomized controlled trials \\
\hline 1b & Individual randomized controlled trials \\
\hline 1c & All-or-none studies \\
\hline 2a & Systematic reviews of cohort studies \\
\hline 2b & Individual cohort studies or low-quality randomized controlled trials \\
\hline 2c & Outcome research \\
\hline $3 \mathrm{a}$ & Systematic reviews of case-control studies \\
\hline $3 \mathrm{~b}$ & Individual case-control studies \\
\hline 4 & Case series, poorly designed cohort or case-control studies \\
\hline 5 & Animal and bench research, expert opinion \\
\hline
\end{tabular}

$* * * * * *$ 